\title{
Indicators of Hypoxia Tolerance as Determined by Cellular Elements of Rat Blood
}

\author{
M. V. Kondashevskaya ${ }^{a, *}$, K. A. Artemieva ${ }^{a}$, V. V. Aleksankina ${ }^{a}$, \\ N. B. Tikhonova ${ }^{a}$, and M. N. Boltovskaya ${ }^{a}$ \\ ${ }^{a}$ A.P. Avtsyn Research Institute of Human Morphology, Moscow, Russia \\ *e-mail: marinavladi2177@yandex.ru
}

Received March 25, 2021

Revised June 10, 2021

Accepted June 28, 2021

\begin{abstract}
Although hypoxia tolerance is mainly determined genetically, it is important to study individual variability of animal organisms in order to identify the factors that underlie their tolerance to hypoxic exposure. We investigated blood cell counts and coagulograms in Wistar rats as predictors allowing the animal population to be split into hypoxia-tolerant and hypoxia-intolerant individuals. The validity of the specific predictors' choice was proved by a coincidence between the population split in accordance with the detected individual parameters and the results of testing animals in a decompression chamber at a rarefaction corresponding to the "rise to an altitude" of $11500 \mathrm{~m}$ above sea level. Circulating blood cells were quantitatively assessed by eighteen indicators before and after hypoxic exposure. The differences between animals low-tolerant (LT), high-tolerant (HT), and medium-tolerant (MT) to hypoxia were determined by five indicators: white blood cell count (WBC), granulocyte count (Gran\#), red blood cell count (RBC), reticulocyte count/percent (RTC), and mean corpuscular hemoglobin $(\mathrm{MCH})$. The $\mathrm{RBC}, \mathrm{RTC}$, and $\mathrm{MCH}$ values in HT rats were significantly higher than in LT animals (by 1.4, 1.9, and 1.1 times, respectively). The WBC and Gran\# values in HT rats were lower than in LT individuals. The hypoxia tolerance indices (HTI) were calculated using the original formula. It was established that in LT rats, the HTI $\leq 0.203$, in HT rats $\geq 0.335$, and in MT rats $<0.335$ but $>0.203$. After testing in a decompression chamber, the activated partial thromboplastin time (APTT), thrombin time (TT), and prothrombin time (PT) decreased, but the fibrinogen level increased. LT rats were characterized by the lowest APTT, TT, and PT values and the highest values of the fibrinogen level. Our results indicate that one of the most important mechanisms underlying a high hypoxia tolerance in rats consists in sustaining reciprocal relationships between the complex of RBC indicators, which tend to increase under hypoxia, and Gran\# indicators, which tend to decrease after hypoxic exposure.
\end{abstract}

DOI: $10.1134 / \mathrm{S} 002209302106003 \mathrm{X}$

Keywords: hypoxia tolerance, blood cells, Wistar rats, coagulogram

\section{INTRODUCTION}

It has long been known that virtually all dis- eases, no matter infectious or noninfectious, as well as in extreme stressful conditions, cause pathological endogenous hypoxia (low oxygen 
content) [1, 2]. Specifically, hypoxia is one of the pathogenetic mechanisms, as well as a factor, that determines the resistance to standard methods of cancer therapy [3]. With a decrease, for whatever reason, in the efficiency of tissue oxygen supply, there are microvascular dysregulation, extravasation and activation of white blood cells (WBCs) in the zone of hypoxic microenvironment. There are many types of immune and pro-inflammatory resident cells, infiltrating this zone in a state of activation, which produce significant amounts of reactive oxygen species leading to oxidative stress, oxidative damage and mitochondrial dysfunction in most of the surrounding cells. The majority of the cells infiltrating the hypoxic zone is represented by activated neutrophils that release procoagulant bioactive substances into the extracellular space [4]. Generally, all processes caused by hypoxia, oxidative stress and mitochondrial dysfunction provoke the secretion of signaling molecules that additionally stimulate the inflammatory response $[5,6]$. This situation is often accompanied by a damage to the endothelial glycocalyx, which performs the anticoagulant function. This results in a release of such procoagulant endothelial products as endothelin-1, superoxide anions, and thromboxane A2, as well as a decrease in the bioavailability of nitric oxide (NO) $[6,7]$. Consolidation of the prothrombotic effects of neutrophils and endothelium leads to the formation of a "vicious circle" of the processes that enhance dysfunction of the anticoagulant system, causing the dominance of the blood coagulation system and the possibility of transition of a local inflammatory reaction to a systemic level [4].

The individual threshold of sensitivity to oxygen deficiency, directly related to genetic factors, largely determines the duration and severity of diseases [8, 9]. The study of the relationship between the tolerance to hypoxia and the peculiarities of biochemical, cellular, organ and phenotypic properties of the animal organism, aimed at extrapolating the obtained information to humans, is important for solving the senescence problems, as well as increasing the tolerance to hypoxia in various diseases and the working capacity of people engaged in professions associated with large psychophysiological and environ- mental loads. This is the most common cause of anthropogenic impacts associated with air pollution, one of the effects of which is a reduction in the oxygen concentration.

At present, the priority trend in experimental biology and medicine is searching for biomarkers of animal tolerance and receptivity to hypoxia in order to determine therapeutic targets for the modeling of various human diseases and implementation of an individual approach to treatment. In most cases, it becomes necessary to split the population of laboratory animals into low-tolerant (LT), medium-tolerant (MT), and high-tolerant (HT) to hypoxia before starting the experiment. Most often, researchers work with groups of animals that differ sharply in all parameters, i.e. with LT and HT. Currently, it is known that LT individuals are characterized by uneconomical consumption of oxygen - they consume a lot more oxygen per unit mass of tissue per unit time than HT individuals, whereas HT animals have developed the mechanisms for more effective adaptation to hypoxia, enabling them to withstand prolonged exposure to oxygen deficiency [10]. To divide the population of laboratory animals, they are tested individually in a decompression chamber, where conditions of acute hypoxia are created. Several types of hypoxia are reproduced in biomedical research, with the imitation of exogenous hypobaric hypoxia being the most commonly used [11]. This situation is artificially reproduced by a controlled pumping air out of a decompression chamber, thus a decrease in the environmental oxygen content leads to a decrease in the oxygen tension $\left(\mathrm{pO}_{2}\right)$ in the alveoli and arterial blood of the animal. Secondary tissue hypoxia develops in animals as a result of a decrease in the oxygen tension in blood and tissues to levels below critical, at which the rate of oxygen utilization (consumption) in tissues begins to go down. If the strength and/or duration of hypoxic exposure exceed the adaptive capabilities of the body, then irreversible changes will appear in organs and tissues and the animal will die.

Due to the fact that testing in a decompression chamber can damage the central nervous system and even cause death of animals, it is necessary a longer (at least 10-month) recovery period for the survived individuals to be involved in further 
experiments. The topical task is to reveal the relationship between certain physiological indicators in the pre-hypoxic period and the level of hypoxia tolerance $[9,12]$. Any hypoxic situation induces a complex of responses, which involves all the functional systems of the organism. The main and most well-known factor mediating this response is the HIF-1 transcription complex (HIF- $1 \alpha$ and HIF-1 $\beta$ subunits) produced by most cells in response to oxygen deficiency. HIF-1 $\beta$ is a constitutively expressed subunit, whereas HIF-1 $\alpha$ is an oxygen-regulated subunit [13]. It has been shown that the level of HIF-1 $\alpha$ expression in human and animal WBCs varies, which indicates phenotypic differences in its regulation [14, 15]. However, HIF-1 $\alpha$ is difficult to use as a predictor of hypoxia tolerance due to significant changes in its level depending on many factors. Since the contribution of HIF- $1 \alpha$ to the pathogenesis of any diseases, as a rule, constantly changes, the issue of targeted pharmacological impacts on HIF-1 $\alpha$ for the addressed regulation of the processes of urgent and long-term adaptation to hypoxia in animals and humans is quite ambiguous [16]. The same is true for many neuroimmunoendocrine indicators.

Undoubtedly, blood appears the most attractive object of studies aimed at identifying predictors of hypoxia, since it is the main conduit for transporting oxygen from the lungs to tissues and carrying carbon dioxide in the opposite direction. Under any environmental challenges, including hypoxia, erythroid cells continue to perform their specific functions, while changing their numbers, size, oxygen content, etc. Under hypoxic conditions, WBCs, in small laboratory rodents mainly represented by neutrophils, are activated. It was determined, that one of the activators is HIF- $1 \alpha$, which plays a crucial role in the regulation of cellular responses to hypoxia. Activated WBCs can affect coagulation directly by producing procoagulant and anticoagulant molecules, and/or indirectly by affecting platelets and endothelial cells. The appearance of a large number of activated WBCs can slow down the movement of red blood cells (RBCs), become a direct cause of microvessel occlusion, and reduce the efficacy of oxygen transportation by blood, thus provoking hypoxia in the microcirculation $[17,18]$.

We assumed that the analysis of blood cell parameters in the pre-hypoxic period would allow the identification of predictors of the tolerance to acute hypoxic hypoxia. Therefore, the objective of this work was to study the cellular composition and coagulation system of the peripheral blood in Wistar rats before and after testing in a decompression chamber, and then to distinguish a number of indicators as predictors allowing the rat population to be split on the basis of hypoxia tolerance.

\section{MATERIALS AND METHODS}

The study was carried out on 40 sexually mature male Wistar rats obtained from the "Stolbovaya" (a branch of the Scientific Center of Biomedical Technologies of the Federal Medical and Biological Agency of Russia) with a body weight of 180$200 \mathrm{~g}$. Animals that had been quarantined for at least 14 days were kept in standard vivarium conditions (randomly allocated by 10 individuals per cage) under natural lighting at a temperature of $20-22^{\circ} \mathrm{C}$, with ad libitum access to water and pelleted food (GOST 34566-2019). All experimental procedures were carried out in compliance with the Directive of the European Parliament 2010/ 63/EU "On the protection of Animals used for Experimental Purposes" (dated 22.09.2010). The study was approved the Bioethics Committee of the A.P. Avtsyn Research Institute of Human Morphology.

The personalized hypoxia tolerance of animals was determined by modeling acute hypoxic hypoxia in a decompression chamber. To achieve the similarity of recording conditions, testing was carried out in the morning (9-11 a.m.), considering the phase of infradian biorhythms, i.e. multiday (by to our data, 4-day), periodically recurring fluctuations in the intensity of many parameters in animals and humans [9, 19]. Namely, testing was performed between acrophase and bathyphase. i.e. the highest and lowest values of corticosterone levels, locomotor activity, etc.

Hypoxia tolerance was determined by measuring the time taken for the onset of gasping (gasping time). Rats were exposed, one at a time, to simulated hypobaric hypoxia caused by a rarefaction equivalent to the "rise to an altitude" of $11500 \mathrm{~m}$ above sea level, in a decompression 
chamber coupled to a mercury barometer (equivalent to $180 \mathrm{~mm} \mathrm{Hg}$ ). All the decompression and recompression instances were achieved gradually at a rate of $80 \mathrm{~m} / \mathrm{s}$ to prevent any tissue injury due to a sudden fall or rise in the ambient pressure. Rats that had an impaired postural reflex "at an altitude" for less than 3 min were considered lowtolerant (LT), more than 9 minutes-high-tolerant (HT), more than 3 minutes, but less than 9 minutes - medium-tolerant (MT ) [20].

Peripheral blood was collected from the caudal vein under zoletil anesthesia $(5 \mathrm{mg} / 100 \mathrm{~g}$, Virbac Santй Animale, France) into test tubes with EDTA as an anticoagulant, a day before the simulation of acute hypoxic hypoxia and 5-10 $\mathrm{min}$ thereafter. The blood count was carried out for to 18 parameters, using a Mindray BC-2800 Vet Automatic Hematology Analyzer (China) with Rat software (WBC, Lymph\#, Mon\#, Gran\#, Lymph\%, Mon\%, Gran\%, RBC, HGB, HCT, MCV, MCH, MCHC, RDW, PLT, MPV, PDV, RTC). Parameters of hemostasis were determined by using a KC4 Delta Semi Automated Hemostasis Analyzer (Tcoag, Ireland). The serum corticosterone concentration was determined by Enzyme-Linked Immunosorbent Assay (ELISA, IBL, Germany).

Statistical data analysis was carried out using Statistica 8.0. Normal distribution was checked by the Shapiro-Wilk test. It was found that the empirical distribution of our data is different from the normal. For statistical processing, nonparametric methods for paired samples was used, the Mann-Whitney $U$-test and the WilcoxonMann-Whitney $t$-test. The results were expressed as the median and interquartile range Me (25$75 \%)$. The differences were considered significant at $p<0.05$.

\section{RESULTS}

The analysis of all blood parameters with categorization of blood cells into drement in blood indicators vs. the mean in a given group, bacmean background value of blood indicators in a given group, $\mathrm{RBC}$ - absolute number of red blood cells, $\mathrm{MCH}-$ mean corpuscular hemoglobin level in the red blood cell, RTC-percent of reticulocytes vs. the total number of red blood cells,
WBC-absolute number of white blood cells, Gran\#-absolute number of granulocytes.

It was found that normal hypoxia tolerance indices are characterized by the values $\leq 0.203$ (LT rats), $\geq 0.335$ (HT rats), and $<0.335$ but $>$ 0.203 (MT rats).

The major evidence that such indicators as the absolute number of WBCs, granulocytes and $\mathrm{RBCs}$, as well as the percent of reticulocytes vs. the total number of red blood cells, and mean corpuscular hemoglobin in red blood cells can be predictors of hypoxia tolerance in rats was obtained when testing animals in a decompression chamber. It was found that "at an altitude" LT rats had impaired postural reflex for less than 3 min. In almost all cases, LT animals began rushing about the decompression chamber, not reaching the maximum "altitude" of $11500 \mathrm{~m}$; some of them showed signs of seizures; 3 rats died after testing. MT animals endured a maximum "altitude" for no longer than $9 \mathrm{~min}$. The behavior of these rats was characterized by anxiety and vigorous running at the onset of reaching a maximum "altitude", calming down after 4-5 minutes. HT individuals were distinguished by a pronounced calmness and the ability to stay at an "altitude" of $11500 \mathrm{~m}$ for more than $9 \mathrm{~min}$. Of the population of 40 rats, $30 \%$ turned out to be HT, $40 \%$ LT, and $30 \%$ MT. It should be emphasized that the individual values of the hypoxia tolerance index (HTI) in HT, MT, and LT rats, determined during testing in a decompression chamber, coincided in their HTI values obtained before testing.

Such cellular components of blood as WBCs, specifically granulocytes, make a significant contribution to hemostasis, which has a strong influence on oxygen transport and utilization in tissues and, accordingly, on hypoxia tolerance [22-24]. In this regard, we studied hemostasis in rats before and after testing in a decompression chamber.

It was found that values of hemostasis' indicators of naive HT, LT and MT rats did not have statistically significant differences, whereas after testifferent subpopulations allowed us to reveal statistically significant differences between rats low-tolerant (LT), high-tolerant (HT) and medium-tolerant (MT) to hypoxia only in five parameters: white blood cell counts (WBC), granulocyte counts (Gran\#), red blood cell counts 
Table 1. Hematological indicators of rats high-tolerant (HT) and low-tolerant (LT) to hypoxia before and after testing in a decompression chamber ( $\mathrm{DpCh})$, Me (25-75\%)

\begin{tabular}{|c|c|c|c|c|c|c|}
\hline Phenotypes & Condition & $\begin{array}{l}\text { Absolute num- } \\
\text { ber of red blood } \\
\text { cells (RBC) } \\
\quad \times 10^{12} / \mathrm{L}\end{array}$ & $\begin{array}{c}\text { Reticulocyte } \\
\text { (RTC), \% of } \\
\text { RBC }\end{array}$ & $\begin{array}{l}\text { Mean corpus- } \\
\text { cular haemo- } \\
\text { globin in RBC } \\
(\mathrm{MCH}), \mathrm{pg}\end{array}$ & $\begin{array}{l}\text { Absolute num- } \\
\text { ber of white } \\
\text { blood cells } \\
\text { (WBC) } \times 10^{9} / \mathrm{L}\end{array}$ & $\begin{array}{c}\text { Absolute number of } \\
\text { granulocytes } \\
(\text { Gran\# }) \times 10^{9} / \mathrm{L}\end{array}$ \\
\hline \multirow[t]{7}{*}{ HT (1) } & \multirow{4}{*}{$\begin{array}{c}\text { before } \mathrm{DpCh} \\
\text { (3) }\end{array}$} & 9.2 & 3.2 & 20.1 & 8.8 & 2.9 \\
\hline & & $(4.7-11.7)$ & $(1.8-4.4)$ & $(19.7-21.2)$ & $(4.3-12.9)$ & $(2.3-3.6)$ \\
\hline & & $p 1-2<0.001$ & $p 1-2<0.001$ & $p 1-2<0.001$ & $p 1-2<0.001$ & $p 1-2<0.001$ \\
\hline & & $p 3-4<0.001$ & $p 3-4<0.001$ & $p 3-4<0.001$ & $p 3-4<0.001$ & $p 3-4>0.05$ \\
\hline & \multirow{3}{*}{$\begin{array}{c}\text { after DpCh } \\
\text { (4) }\end{array}$} & 12.3 & 9.2 & 22.1 & 13.1 & 5.1 \\
\hline & & $(9.2-13.9)$ & $(5.1-12.6)$ & $(21.8-31.1)$ & $(8.8-16.6)$ & $(3.3-6.1)$ \\
\hline & & $p 1-2<0.001$ & $p 1-2<0.001$ & $p 1-2<0.001$ & $p 1-2<0.001$ & $p 1-2<0.001$ \\
\hline \multirow[t]{5}{*}{ LT (2) } & \multirow{3}{*}{$\begin{array}{c}\text { before } \mathrm{DpCh} \\
\text { (5) }\end{array}$} & 6.4 & 1.7 & 19.1 & 19.2 & 3.7 \\
\hline & & $(3.9-9.3)$ & $(0.8-2.6)$ & $(18.5-19.7)$ & $(11.9-29.8)$ & $(3.8-4.6)$ \\
\hline & & $p 5-6<0.001$ & $p 5-6<0.001$ & $p 5-6>0.05$ & $p 5-6<0.001$ & $p 5-6<0.001$ \\
\hline & \multirow{2}{*}{$\begin{array}{c}\text { after DpCh } \\
\text { (6) }\end{array}$} & 8.5 & 4.8 & 19.9 & 36.6 & 7.4 \\
\hline & & $(5.9-11.9)$ & $(1.6-5.2)$ & $(18.9-21.5)$ & $(22.9-54.7)$ & $(5.9-8.9)$ \\
\hline
\end{tabular}

( $\mathrm{RBC}), \%$ reticulocyte (RTC) and mean corpuscular hemoglobin $(\mathrm{MCH})$. The RBC, RTC and $\mathrm{MCH}$ values were significantly higher in HT rats than in LT animals (by 1.4, 1.9 and 1.1 times, respectively) both before and after testing in a decompression chamber, as can be seen in Table 1. The Gran\# and WBC indicators in HT individuals were much lower than in LT rats under the same conditions (Table 1). For instance, while in HT individuals the normal WBC was 2.2 times and the Gran\# 1.3 times lower, after testing in a decompression chamber, the differences were 2.8 and 1.5 times, respectively (Table 1). Overall, immediately after testing in a decompression chamber, all blood cell parameters were found to increase in all animals (Table 1). The values of the same indicators were higher in MT compared to LT rats, but lower than the HT individuals. Since many hematological parameters of MT rats were statistically indistinguishable from those in LT and HT animals, their values are not shown Tables 1, 2 .

Since the amplitudes and units of measurement for blood parameters showed a great dispersion [21], we developed a formula to calculate the hypoxia tolerance index (HTI) based on the formula for the integrative assessment of functional reserves of an organism:

$$
\mathrm{HTI}=1 / \sqrt{\left(\frac{\Delta \mathrm{RBC}}{\mathrm{RBC}_{\mathrm{bac}}}\right)^{2}+\left(\frac{\Delta \mathrm{MCH}}{\mathrm{MCH}_{\mathrm{bac}}}\right)^{2}+\left(\frac{\Delta \mathrm{RTC}}{\mathrm{RTC}_{\mathrm{bac}}}\right)^{2}+\left(\frac{\Delta \mathrm{WBC}}{\mathrm{WBC}_{\mathrm{bac}}}\right)^{2}+\left(\frac{\Delta \mathrm{Gran} \#}{\mathrm{Gran}_{\mathrm{bac}}}\right)^{2}},
$$

where $\Delta$-incing in a decompression chamber, the APTT, TT and PT values decreased, and the levels of fibrinogen increased (Table 2). It was shown that LT animals were characterized by the lowest values of APTT, TT and PT and the highest levels of fibrinogen (Table 2).
Serum corticosterone levels did not differ significantly between animals with different hypoxia tolerance before and after testing in a decompression chamber (Table 2). The corticosterone content increased significantly after the hypoxia, as in any case of acute stress (Table 2) [25].

JOURNAL OF EVOLUTIONARY BIOCHEMISTRY AND PHYSIOLOGY Vol. 57 No. 62021 
Table 2. Indicators of hemostasis and corticosterone levels in rats high-tolerant (HT) and low-tolerant (LT) to hypoxia before and after testing in a decompression chamber $(\mathrm{DpCh}), \mathrm{Me}(25-75 \%)$

\begin{tabular}{|c|c|c|c|c|c|c|}
\hline Phenotypes & Condition & APTT, s & $\mathrm{TT}, \mathrm{s}$ & $\mathrm{PT}, \mathrm{s}$ & $\begin{array}{c}\text { Fibrinogen level, } \\
\mathrm{g} / \mathrm{L}\end{array}$ & $\begin{array}{c}\text { Corticosterone level, } \\
\mathrm{ng} / \mathrm{mL}\end{array}$ \\
\hline \multirow[t]{7}{*}{ HT (1) } & \multirow{4}{*}{$\begin{array}{c}\text { before } \mathrm{DpCh} \\
\text { (3) }\end{array}$} & 17.3 & 38.4 & 18.6 & 2.3 & 255.6 \\
\hline & & $(15.9-18.3)$ & $(32.9-44.1)$ & $(17.9-19.2)$ & $(2.1-2.4)$ & $(226.2-286.7)$ \\
\hline & & $p 1-2>0.05$ & $p 1-2>0.05$ & $p 1-2>0.05$ & $p 1-2>0.05$ & $p 1-2>0.05$ \\
\hline & & $p 3-4>0.05$ & $p 3-4>0.05$ & $p 3-4>0.05$ & $p 3-4<0.001$ & $p 3-4<0.001$ \\
\hline & \multirow{3}{*}{$\begin{array}{l}\text { after DpCh } \\
\text { (4) }\end{array}$} & 16.4 & 34.6 & 18.3 & 2.5 & 425.3 \\
\hline & & $(12.7-17.5)$ & $(33.3-37.1)$ & $(17.6-19.3)$ & $(2.2-2.7)$ & $(361.4-489.2)$ \\
\hline & & $p 1-2<0.001$ & $p 1-2<0.001$ & $p 1-2<0.001$ & $p 1-2<0.001$ & $p 1-2>0.05$ \\
\hline \multirow[t]{5}{*}{ LT (2) } & \multirow{3}{*}{$\begin{array}{l}\text { before } \mathrm{DpCh} \\
\text { (5) }\end{array}$} & 15.6 & 36.7 & 17.9 & 2.3 & 250.3 \\
\hline & & $(11.5-18.4)$ & $(31.8-40.9)$ & $(16.5-19.1)$ & $(2.1-2.7)$ & $(227.5-267.9)$ \\
\hline & & $p 5-6<0.001$ & $p 5-6<0.001$ & $p 5-6<0.001$ & $p 5-6<0.001$ & $p 5-6<0.001$ \\
\hline & \multirow{2}{*}{$\begin{array}{l}\text { after DpCh } \\
\text { (6) }\end{array}$} & 10.3 & 21.8 & 14.7 & 3.7 & 436.4 \\
\hline & & $(8.5-12.1)$ & $(19.8-24.4)$ & $(13.7-16.1)$ & $(3.4-4.1)$ & $(335.1-531.6)$ \\
\hline
\end{tabular}

\section{DISCUSSION}

In this study, it was found that such indicators of peripheral blood of Wistar rats as the white blood cell count (WBC), granulocyte count (Gran\#), red blood cell count $(\mathrm{RBC})$, reticulocyte count/percent (RTC) and mean corpuscular hemoglobin $(\mathrm{MCH})$ can be used as predictors of hypoxia tolerance. The priority information obtained in the present study is that one of the most important mechanisms that underlie high hypoxia tolerance consists in sustaining reciprocal relationships between the specified set of indicators of the erythroid hemopoietic branch, which tend to increase, and those of the granulocytic branch, which tend to decrease under hypoxia. At the same time, compared to LT, HT animals are characterized by significantly higher values of the $\mathrm{RBC}, \mathrm{RTC}$ and $\mathrm{MCH}$, as well as by lower values of WBCs and Gran\# in naive rats. The same ratio of all these cellular elements remains after testing rats in a decompression chamber. Our data echo the results by L.A. Gridin, who found that hypoxia, as a specific stimulator of erythropoiesis, activates the mechanisms that lead to a compensatory adaptation, i.e. a decrease in the reproduc- tion of white blood cells in the bone marrow [26]. In this study, we recorded, possibly genetically fixed, an increased mobilization readiness of the organism of HT rats to respond to hypoxia or other stressful exposures in the form of a mechanism that suppresses the reproduction of granulocytic cells and boosts the proliferation of erythroid cells. Perhaps this is due to the fact that, in the case of a significant predominance of WBC elements, counter to their protective function, a disaster may result, because granulocytes, which account for the majority of WBCs in animals and humans, instantly respond to an emergency situation by a release of large amounts of toxic substances that also have a negative impact on the host body. In this case, the vascular endothelium can be damaged, causing the activation of the coagulation system. These negative effects of neutrophils, representing a significant portion of the granulocytic elements of the WBC population, are now well documented when studying their action in COVID-19 [27, 28].

Increased blood coagulation plays a significant role in decreasing hypoxia tolerance [29, 30]. In the present work, we established that after being in conditions of acute hypoxic hypoxia, LT rats 
developed a state of hypercoagulation associated with the intrinsic (shortening of the APTT) and extrinsic (shortening of the PT) pathways of activation of blood coagulation, which was aggravated by an increase in fibrinogen levels. This can be explained by a damage to the vascular wall, inflicted by reactive oxygen species, and an increased (vs. HT rats) number of hypoxia-activated granulocytes that release procoagulant factors [17, 24, 31]. Our data are consistent with those obtained by other authors [32-34]. An increase in the blood fibrinogen level in response to stress-induced corticosterone elevation may have been causative for the shortening of the TT indicator, which reflects a fibrinogen-to-fibrin conversion and depends on the blood fibrinogen level [35].

Testing of rats in a decompression chamber proved the fact that individual hypoxia tolerance in rats can be determined by HTI values. Besides hypoxic stimuli, other stress factors also act on living organisms in a decompression chamber. In physiology, at all stages of evolution, it is customary to distinguish two qualitatively different strategies of survival: the active, resident strategy characterized by an active overcoming of stress factors, and passive, tolerance strategy implying a quiet perception of an external stimulus' intervention (a freezing response). These adaptation strategies are provided by different neuroimmunoendocrine mechanisms $[36,37]$. As follows from our data, in a decompression chamber, LT rats demonstrated a distinct resident strategy, due to which oxygen reserves were overspent, and the animals quickly lost the ability to sustain postural reflex. While HT rats held to a tolerance strategy that promoted longterm saving in oxygen consumption, MT rats demonstrated an alteration of strategies, which determined the intermediate values retention time of postural reflex in HT vs. LT rats. The manifestation of behavioral strategies, likewise hypoxia tolerance, is believed to be genetically fixed [37, 38]. As shown in our previous studies, moderate physical loads (swimming) allowed tolerant behavior conditioning in most of Wistar rats in the population. At the same time, it was established that animals adopted to tolerant strategy, became HT, while unlearned rats turned out to be LT [39]. Given that tolerance to hypoxia is geneti- cally fixed and MT rats are probably the most tolerant to hypoxia, it can be assumed that MT rats, which learned the strategy of tolerance as the main principle of their behavior, became HT animals. Our studies give a reason to pose the problem of including behavioral mechanisms in the integrative response of animals and humans to acute hypoxia.

Thus, it has been demonstrated for the first time that HT rats are characterized by an increased mobilization readiness (probably fixed genetically) to respond to hypoxia in the form of suppressing the reproduction of WBCs and boosting erythropoiesis. We also identified the predictors of hypoxia tolerance, namely WBCs, granulocytes, RBCs, RTC, and MCH. We developed an original formula for calculating the hypoxia tolerance index (HTI), which allows splitting the rat population into HT, LT and MT individuals without testing them in a decompression chamber. It was established that in LT rats, the HTI values $\leq$ 0.203 , in HT rats $>0.335$, and in MT rats $<0.335$ but $>0.203$. Prediction of individual tolerance to hypoxia in naive animals is of great interest from both theoretical and practical points of view, since acute hypoxic hypoxia damages the central nervous system, can cause death of animals, and prolongs the recovery period of surviving individuals (up to 1 month) for the involvement in further experiments. The identification of the relationship between certain physiological indicators in naive animals or humans with the level of hypoxia tolerance makes it possible to improve the accuracy of predicting the outcome of acute hypoxic exposure, which is important for the professionals whose activities are associated with a high risk of hypoxia. Moreover, it is important to search for therapeutic targets when modeling various human diseases in order to develop a personalized approach to treatment.

\section{AUTHORS' CONTRIBUTION}

M.V.K.-idea, experimental design, data collection, writing of the article; K.A.A., V.V.A., N.B.T.-technical support during the experiments, participation in data processing and discussion; M.N.B.-data processing and discussion, editing of the article. 


\section{FUNDING}

This work was supported by the Russian Federation's federal budget allotted to the A.P. Avtsyn Research Institute of Human Morphology for the implementation of the governmental assignment AAAA-A19-119021490067-4.

\section{COMPLIANCE WITH ETHICAL STANDARDS}

All applicable international, national and/or institutional principles for the care and use of animals have been observed.

This article did not contain the results of any research involving people as research objects.

\section{CONFLICT OF INTEREST}

The authors declare that they have neither evident nor potential conflict of interest related to the publication of this article.

\section{REFERENCES}

1. Semenza GL (2014) Oxygen sensing, hypoxiainducible factors, and disease pathophysiology. Annu Rev Pathol 9:47-71. https://doi.org/ 10.1146/annurev-pathol-012513-104720

2. Luks AM, Swenson ER, Bärtsch P (2017) Acute highaltitude sickness. Eur Respir Rev 26 (143): 160096. https://doi.org/10.1183/16000617.00962016

3. Multhoff G, Vaupel P (2020) Hypoxia Compromises Anti-Cancer Immune Responses. Adv Exp Med Biol 1232:131-143. https://doi.org/10.1007/ 978-3-030-34461-0_18

4. Chen YC, Ho CW, Tsai HH, Wang JS (2015) Interval and continuous exercise regimens suppress neutrophilderived microparticle formation and neutrophil-promoted thrombin generation under hypoxic stress. Clin Sci (Lond) 128 (7): 425-436. https://doi.org/10.1042/CS20140498

5. McGarry T, Biniecka M, Veale DJ, Fearon U (2018) Hypoxia, oxidative stress and inflammation. Free Radic Biol Med 125:15-24. https:// doi.org/10.1016/j.freeradbiomed.2018.03.042

6. Gonzalez NC, Wood JG (2010) Alveolar hypoxiainduced systemic inflammation: what low $\mathrm{PO}(2)$ does and does not do. Adv Exp Med Biol 662:2732. https://doi.org/10.1007/978-1-4419-1241$1 \_3$
7. Dremina NN, Shurygin MG, Shurygina IA (2016) Endothelins in standard and pathology. International Journal of Applied and Fundamental Research. Medical sciences. 10: 210-214. (In Russ.)

8. Rzhepetskaya MK (2017) Genetic markers as an indicator of human resistance to various environmental and occupational factors. Proceedings of the Russian Military Medical Academy 36 (4): 613 (In Russ.)

9. Dzhalilova DS, Kosyreva AM, Diatroptov ME, Makarova OV (2017) Relationship between Hypoxic Resistance and the Phase of 4-Day Corticosterone Biorhythm in Adult Male Rats. Bull Exp Biol Med 163:687-690. https://doi.org/ 10.1007/s10517-017-3879-7

10. Pavlik LL, Mikheeva IB, Al'-Mugkhrabi YM, Berest VP, Kirova YI, Germanova EL, Luk'yanova LD, Mironova GD (2018) Specific features of immediate ultrastructural changes in brain cortex mitochondria of rats with different tolerance to hypoxia under various modes of hypoxic exposures. Bull Exp Biol Med. 164 (3):376-381. https://doi.org/10.1007/s10517018-3993-1

11. Karkishchenko NN (2017) Biomedical (preclinical) study of antihypoxic activity of drugs. Methodological recommendations. FMBA of Russia, M (In Russ.)

12. Baiburina GA, Nurgalieva EA, Drozdova GA (2016) Influence of extreme hypoxia on the hormonal profile and dynamics of free radical processes in the brain of rats with different phenotypes of resistance to hypoxia. Health and education in the XXI century 18(6): 95-98 (In Russ.)

13. Hirai K, Furusho H, Hirota K, Sasaki H (2018) Activation of hypoxia-inducible factor 1 attenuates periapical inflammation and bone loss. Int $\mathbf{J}$ Oral Sci 10(2):12. https://doi.org/10.1038/ s41368-018-0015-0

14. Brooks JT, Elvidge GP, Glenny L, Gleadle JM, Liu C, Ragoussis J, Smith TG, Talbot NP, Winchester L, Maxwell PH, Robbins PA (2009) Variations within oxygen-regulated gene expression in humans. J Appl Physiol (1985) 106(1):212-220. https://doi.org/10.1152/japplphysiol.90578.2008

15. van Patot MC, Gassmann M (2011) Hypoxia: adapting to high altitude by mutating EPAS-1, the gene encoding HIF-2a. High Alt Med Biol 12(2):157-167. https://doi.org/10.1089/ ham.2010.1099

16. Kabei K, Tateishi Y, Shiota M, Osada-Oka M, Nishide S, Uchida J, Nakatani T, Matsunaga S, 
Yamaguchi T, Tomita S, Miura K (2020) Effects of orally active hypoxia inducible factor alpha prolyl hydroxylase inhibitor, FG4592 on renal fibrogenic potential in mouse unilateral ureteral obstruction model. J Pharmacol Sci 142 (3): 93100. https://doi.org/10.1016/j.jphs.2019.12.002

17. Gaertner F, Massberg S (2016) Blood coagulation in immunothrombosis-At the frontline of intravascular immunity. Semin Immunol 28(6): 561569. https://doi.org/10.1016/j.smim.2016.10.010

18. Tikhomirova I, Petrochenko E, Malysheva Y, Ryabov M, Kislov N (2016) Interrelation of blood coagulation and hemorheology in cancer. Clin Hemorheol Microcirc 64(4):635-644. https:// doi.org/10.3233/CH-168037

19. Kondashevskaya MV, Diatroptov ME (2013) Behavioral Characteristics of Ovariectomied Wistar Rats Trained in a Maze. Effect of Mental Stress and Castration for Infradian Rhythms. Bull Exp Biol Med 155:272-276. https://doi.org/10.1007/ s10517-013-2130-4

20. Dzhalilova DS, Kosyreva AM, Diatroptov ME, Makarova MA, Makarova OV (2019) Liver and lung morphology and phagocytic activity of peripheral blood cells during systemic inflammatory response in male rats with different resistance to hypoxia. Clin Exp Morphol 29:47-55. (In Russ.). https://doi.org/31088/2226-5988- 201929-1-47-55

21. Nagornev SN, Bobrovnitsky SP, Khripach LV, Khudov VV (2017) Immuno-biochemical screening and metabolic load tests in the assessment of functional reserves of the body. Russian Journal of Rehabilitation Medicine 2:3-38 (In Russ.)

22. Finsterbusch M, Schrottmaier WC, Kral-Pointner JB, Salzmann M, Assinger A (2018) Measuring and interpreting platelet-leukocyte aggregates. Platelets 29:677- 685. https://doi.org/10.1080/ 09537104.2018.1430358

23. Lodge KM, Cowburn AS, Li W, Condliffe AM (2020) The Impact of Hypoxia on Neutrophil Degranulation and Consequences for the Host. Int J Mol Sci 21: 1183. https://doi.org/10.3390/ ijms21041183

24. Egners A, Erdem M, Cramer T (2016) The response of macrophages and neutrophils to hypoxia in the context of cancer and other inflammatory diseases. In: Mediators Inflamm. Article ID 2053646. https://doi.org/10.1155/2016/ 2053646

25. Obernikhin SS, Yaglova NV, Nazimova SV, Yaglov VV, Timokhina EP (2019) Transcriptional regulation of morphogenesis of rat adrenal zona glomerulosa during postnatal development. Clin
Exp Morphol 8:48-54. (In Russ.) https://doi.org/ 10.31088/2226-5988-2019-30-2-48-54

26. Gridin LA (2016) Modern ideas about the physiological and therapeutic and preventive effects of hypoxia and hypercapnia. Journal of Medicine 3:45-68 (In Russ.)

27. Lv D, Xu Y, Cheng H, Ke Y, Zhang X, Ying K (2020) A novel cell-based assay for dynamically detecting neutrophil extracellular traps-induced lung epithelial injuries. Exp Cell Res 394:112101. https://doi.org/10.1016/j.yexcr.2020.112101

28. Colling ME, Kanthi Y (2020) COVID-19-associated coagulopathy: An exploration of mechanisms. Vasc Med 25:471-478. https://doi.org/ $10.1177 / 1358863 X 20932640$

29. Shang C, Wuren T, Ga Q, Bai Z, Guo L, Eustes AS, McComas KN, Rondina MT, Ge R (2020) The human platelet transcriptome and proteome is altered and prothrombotic functional responses are increased during prolonged hypoxia exposure at high altitude. Platelets 31:33-42. https://doi.org/10.1080/09537104.2019.1572876

30. Viecca M, Radovanovic D, Forleo GB, Santus P (2020) Enhanced platelet inhibition treatment improves hypoxemia in patients with severe Covid-19 and hypercoagulability. A case control, proof of concept study. Pharmacol Res 158: 104950. j.phrs.2020.104950

31. Li X, Yang Y, Liu L, Yang X, Zhao X, Li Y, Ge Y, Shi Y, Lv P, Zhang J, Bai T, Zhou H, Luo P, Huang S (2020) Effect of combination antiviral therapy on hematological profiles in 151 adults hospitalized with severe coronavirus disease 2019. Pharmacol Res 160: 105036. https://doi.org/ 10.1016/j.phrs.2020.105036

32. Tyagi T, Ahmad S, Gupta N, Sahu A, Ahmad Y, Nair V, Chatterjee T, Bajaj N, Sengupta S, Ganju L, Singh SB, Ashraf MZ (2014) Altered expression of platelet proteins and calpain activity mediate hypoxia-induced prothrombotic phenotype. Blood 123 (8): 1250-60. https://doi.org/ 10.1182/blood-2013-05-501924

33. O'Brodovich HM, Andrew M, Gray GW, Coates G (1984) Hypoxia alters blood coagulation during acute decompression in humans. J Appl Physiol Respir Environ Exerc Physiol 56(3):666670. https://doi.org/10.1152/jappl.1984.56.3.666

34. Bärtsch P, Haeberli A, Hauser K, Gubser A, Straub PW (1988) Fibrinogenolysis in the absence of fibrin formation in severe hypobaric hypoxia. Aviat Space Environ Med 59 (5): 428-432.

35. Atencio AC, Chao PY, Chen AY, Reeve EB (1969) Fibrinogen response to corticotropin 
preparations in rabbits. Am J Physiol 216(4):773780. acy.1969.216.4.773

https://doi.org/10.1152/ajpleg-

36. Tseilikman VE, Tseilikman OB, Sinitsky AI, Levin E, Lapteva IA, Gornostaeva AB, Borisenkov AB, Nusratov MI, Romanov DA (2008) Biochemical strategies of adaptation in conditions of chronic stress. Bulletin of South Ural State University 4: 56-57 (In Russ).

37. Baiburina GA, Nurgaleeva EA, Nikitina IL, Bulygin KV, Samigullina AF, Agletdinov EF (2017) The relationship between the levels of circulating corticosterone, the expression of central corticosteroid receptors, and changes in the behavioral activity of rats with different resistance to hypoxia in the dynamics of recovery after extreme hypoxia.
Modern problems of science and education 4:3657 (In Russ).

38. Perez-Tejada J, Garmendia L, Labaka A, Vegas O, Gymez-Lazaro E, Arregi A (2019) Active and passive coping strategies: comparing psychological distress, cortisol, and proinflammatory cytokine levels in breast cancer survivors. Clin J Oncol Nurs 23(6):583-590. https://doi.org/ 10.1188/19.CJON.583-590

39. Kondashevskaya MV (2020) Specific Behavioral Patterns Enhancing Hypoxia Resistance in Wistar Rats Subjected to Moderate Swimming Exercise. Bull Exp Biol Med 169(2):205-208. https:// doi.org/10.1007/s10517-020-04851-4

Translated by A. Polyanovsky 